\title{
A periodização histórico-cultural e o desenvolvimento da linguagem: contribuições ao trabalho pedagógico na educação infantil
}

\author{
Historic-cultural periodization and the language development: the \\ contributions to pedagogical work in early childhood education
}

\section{Maria Cláudia da Silva Saccomani ${ }^{1}$}

\begin{abstract}
RESUMO
Partindo da compreensão histórico-cultural de desenvolvimento humano, fundamentamo-nos na ideia de que o trabalho pedagógico na educação infantil deve se sustentar pela tríade conteúdo-forma-destinatário. Diante disso, a periodização do desenvolvimento é um instrumento importante para compreender o destinatário e organizar o trabalho pedagógico. Assim, apresentamos neste artigo os três primeiros períodos do desenvolvimento infantil, descrevendo as atividades-guia e as respectivas características da linguagem esperadas em cada período. A compreensão deste processo de desenvolvimento na infância permite que o professor possa analisar, planejar e organizar sua prática docente tendo em vista o máximo desenvolvimento da linguagem oral, de acordo com as especificidades da faixa etária.
\end{abstract}

\begin{abstract}
Starting from the historical-cultural understanding of human development, we are based on the idea that the pedagogical work in early childhood education must support itself by the triad form-content-receiver. Therefore, the periodization of development is an important instrument to understand the receiver and to organize the pedagogical practice. Thus, we present in this article the first three periods of the child's development, describing the guiding activities and the respectives language characteristics expected in each period. The understanding of this developmental process in childhood allows the teacher to analyze, plan and organize their teaching practice bearing in mind the maximum development of oral language, according to the specificities of the age group.
\end{abstract}

Keywords: Early childhood education; Oral language; Historical-cultural psychology.

Palavras-chave: Educação infantil;

Linguagem oral; Psicologia históricocultural.

\section{Introdução}

Este artigo apresenta parte de nossa pesquisa de doutorado, um estudo de natureza teórico-conceitual, fundamentado na pedagogia histórico-crítica e na psicologia histórico-cultural, que teve como objetivo contribuir para o planejamento pedagógico na educação pré-escolar tendo em vista o ensino desenvolvente da língua portuguesa (SACCOMANI, 2018). Nessa direção, o

\footnotetext{
1 Doutora em Educação Escolar pela UNESP, campus de Araraquara. Professora de Ensino Básico, Técnico e Tecnológico da Unidade de Atendimento à Criança (UAC) - UFSCar. E-mail: mariaclaudiasaccomani@hotmail.com
} 
objeto deste texto é a relação entre ensino escolar e o desenvolvimento da linguagem no contexto particular da educação infantil, dado o papel decisivo que a fala desempenha no desenvolvimento do psiquismo humano.

Partindo do princípio de que a organização do trabalho pedagógico se sustenta na tríade conteúdo-forma-destinatário (MARTINS, 2013a) e considerando que o grau de complexidade do conteúdo e a forma de realização do trabalho didático são determinados pelo destinatário do processo educativo (MARSIGLIA e SAVIANI, 2017), faz-se necessário que professores de educação infantil conheçam o desenvolvimento da linguagem na criança para subsidiar o trabalho pedagógico.

À medida que o texto buscar trazer contribuições ao trabalho pedagógico com as crianças pequenas, é importante esclarecer que a psicologia históricocultural, embora ofereça elementos essenciais para fundamentar o trabalho educativo, não se caracteriza como teoria pedagógica e, portanto, não é capaz de, por si só, organizar a prática pedagógica. Daí que resulta incoerente uma transposição direta da psicologia à educação escolar (MARTINS, 2013b).

É essencial compreender as leis que regem o desenvolvimento infantil para desenvolver metodologias eficientes, identificar a natureza e o grau de complexidade dos conteúdos a serem ensinados. Diante disso, psicologia e pedagogia devem ser entendidas como unidade que orienta o trabalho docente, sem, porém, ascender a psicologia à posição de guia do trabalho educativo em detrimento da análise e definição de quais conteúdos serão ensinados (PASQUALINI e ABRANTES, 2013), o que é uma das tarefas da pedagogia.

Com efeito, o presente texto se debruça sobre as particularidades do psiquismo infantil e busca subsídios para a ação pedagógica, uma vez que a teoria da periodização do desenvolvimento psíquico é um instrumento importante para compreender o destinatário e organizar o trabalho pedagógico tendo em vista o desenvolvimento da linguagem oral.

\section{$2 \mathrm{O}$ desenvolvimento histórico-cultural da linguagem}

Conforme Martins (2013a), o psiquismo humano como sistema interfuncional abarca os processos funcionais sensação, percepção, atenção, 
memória, linguagem, pensamento, imaginação, emoções e sentimentos. Esses processos, como defende a autora, são os responsáveis pela formação da imagem subjetiva da realidade objetiva, que apenas se institui nas e por meio das relações que se edificam entre as funções, o que impossibilita qualquer enfoque sobre as funções psíquicas que as compreenda de forma fragmentada da totalidade da qual são parte, especialmente quando nos dedicamos à linguagem, cuja internalização requalifica o desenvolvimento de todas as demais funções.

A apropriação e desenvolvimento da linguagem não se restringe à habilidade de aprender a falar e articular determinados sons que representam os objetos da realidade. A compreensão do que seja o desenvolvimento da linguagem demanda saber a sua importância à complexificação do psiquismo, compreendendo-a como uma das mais complexas funções, cujo funcionamento se vincula com a complexificação das demais, em especial, com o pensamento.

Por meio da internalização dos signos, as funções psíquicas são transformadas e se convertem em processos mediados (MARTINS, 2016). Nessa perspectiva, o signo é um elemento da realidade que designa ou substitui outro, um sinal dotado de significação. Para Vigotski (2009), o principal sistema de signos de que dispomos é a linguagem e, portanto, destaca a palavra como signo dos signos. Enquanto forma elaborada de significação, a palavra é um signo que designa um objeto, substituindo-o.

Como mostra-nos Luria (1979), a palavra designa objetos da realidade. Graças a isso, o ser humano é capaz de operar com os objetos mentalmente, libertando-se do campo sensorial imediato. Assim, a palavra possui uma referência objetal, mas vai além de seu papel designativo, uma vez que também analisa e generaliza, abstraindo suas propriedades.

Há que se destacar, pois, que a palavra não se refere apenas a um único objeto, o significado cumpre a função de separação de determinados traços do objeto, sua generalização e introdução em determinada categoria, o que é denominado por Luria (2001) de significado categorial. Segundo o referido autor, "[...] a palavra não é somente um meio de substituição das coisas, é a célula do pensamento, precisamente porque a função mais importante do pensamento é a abstração e generalização. ” (idem, p. 37). É nesse sentido que, como afirma Vigotski (2009, p.9), toda palavra “[...] é antes de tudo uma generalização”. 
No desenvolvimento da linguagem na ontogênese, os signos não são inventados pelas crianças, como mostrou Vygotski (2000); elas recebem a linguagem das pessoas e apenas depois descobrem suas funções como signos. Em um primeiro momento, os signos aparecem por meio de processos interpsíquicos, isto é, as objetivações humanas são disponibilizadas para cada sujeito por meio da relação com outros sujeitos e à medida que são internalizados pelo indivíduo, firmam-se como processos intrapsíquicos. Portanto, a apropriação da linguagem demanda processos educativos, posto que existe, primeiro, na relação da criança com o outro, para depois, tornar-se uma conquista da própria criança.

Martins (idem) ressalta a conexão direta entre linguagem e pensamento, destacando a dialeticidade existente no desenvolvimento histórico e cultural de ambos. Diante disso, linguagem e pensamento possuem especificidades, pois como afirma Rubinstein (1967), a relação entre esses processos funcionais é de unidade e não de identidade. A unidade, segundo Vigotski (2009), está no significado da palavra, que é tanto fenômeno da linguagem quanto do pensamento.

Contudo, a unidade entre pensamento e linguagem não existe no desenvolvimento da criança do ponto de partida. Vigotski (idem) explica que essas funções psíquicas têm raízes genéticas diferentes no desenvolvimento psíquico do ser humano, assim como trilham caminhos diferenciados entre si nesse percurso. Destarte, no desenvolvimento do pensamento há uma fase prélinguistíca, assim como no desenvolvimento da fala há uma fase pré-intelectual.

$\mathrm{Se}$, do ponto de partida, não existe a unidade entre pensamento $\mathrm{e}$ linguagem, em determinado momento do desenvolvimento, aproximadamente aos dois anos, acontece o entrecruzamento entre essas duas funções psíquicas, de modo que "[...] a fala se torna intelectual e o pensamento verbalizado" (VIGOSTSKI, 2009, p. 131, grifo do autor). Portanto, a aliança entre pensamento e linguagem não é um dado natural, mas produzida socialmente.

Sendo a linguagem o mais importante dos signos, pretendemos abordar como se dá o processo de desenvolvimento dessa objetivação humana na criança de 0 a 5 anos, tendo em vista as maneiras particulares como a criança se relaciona com a linguagem nos diferentes momentos da vida. 


\section{A periodização histórico-cultural e o desenvolvimento da linguagem}

A concepção de desenvolvimento que fundamenta a periodização é histórica e cultural e, portanto, a subjetividade não pode ser entendida alheia à forma como o indivíduo está inserido na sociedade, o que ratifica o papel da educação escolar na sociedade de classes de socializar o conhecimento historicamente acumulado para todos e promover as máximas possibilidades de desenvolvimento dos sujeitos, como defende a pedagogia histórico-crítica.

Nessa perspectiva da periodização, a idade cronológica é apenas referencial e não determinante, já que a transição de um período a outro não acontece naturalmente, mas é dependente das condições de vida e educação. Nessa direção, Elkonin (1987b), refuta o enfoque naturalista do desenvolvimento e, baseando-se no conceito de atividade-guia de Leontiev (2012a), traz a compreensão das forças motrizes do desenvolvimento psíquico nos diferentes períodos da vida. Em cada momento particular do desenvolvimento, há uma atividade-guia, que como o próprio nome indica, são atividades que guiam o desenvolvimento psíquico da pessoa em cada período e direcionam as mudanças psicológicas mais decisivas, enquanto outras atividades coexistem, mas exercem um papel secundário na promoção do desenvolvimento.

É na atividade-guia que novas atividades são engendradas, processos psíquicos são colocados em movimento, transformando a relação da pessoa com o mundo e seu modo de ser. Ao mesmo tempo em que direciona as mudanças psicológicas mais decisivas, a atividade-guia cria as premissas para a formação de novos tipos de atividade. Assim, no interior de uma determinada atividadeguia, uma nova atividade começa a ser gestada, ou seja, atividades-guias surgem em períodos anteriores e tornam-se acessórias no período seguinte quando outra atividade é a principal promotora de desenvolvimento.

Com efeito, o professor precisa ter uma visão da totalidade do desenvolvimento ${ }^{2}$, o que engloba aquilo que já é uma conquista da criança (nível de desenvolvimento real), resultante das aquisições do período em que está e dos anteriores e, ao mesmo tempo, daquilo que conduz a transição ao período

2 Para ter uma visão ampla da periodização, vide a obra "Periodização histórico-cultural do desenvolvimento psíquico: do nascimento à velhice (MARTINS, ABRANTES, FACCI, 2016). 
seguinte (área de desenvolvimento iminente). Assim, o trabalho pedagógico deve caminhar em uma via de mão dupla (MARSIGLIA e SACCOMANI, 2016), ou seja, ao mesmo tempo que toma a atividade-guia do período como instrumento da prática pedagógica, tendo como referência as conquistas e possibilidades de desenvolvimento em cada idade, deve também ter como referência o próximo período, engendrando as premissas da atividade-guia que se aproxima. Destarte, o professor deve atuar nas linhas acessórias de desenvolvimento e explorar elementos que impulsionem a transição ao próximo período.

Abordaremos, nesse artigo, os três primeiros períodos do desenvolvimento infantil e as respectivas atividades-guia que perpassam o desenvolvimento da criança na educação infantil, articulando com o curso da linguagem.

\subsection{Primeiro ano de vida: comunicação emocional direta e a etapa pré- linguistíca}

O período de passividade, que caracteriza o recém-nascido, é essencialmente marcado por condicionantes biológicos, tais como reflexos incondicionados de alimentação, defesa e orientação. Esses reflexos, embora sejam de extrema importância na adaptação às condições extrauterinas, são insuficientes para sobrevivência, uma vez que o bebê depende integralmente dos cuidados contínuos dos adultos, que satisfazem todas as suas necessidades (ELKONIN, 1960). É nesse sentido que, como afirma Martins (2012), o bebê não pode ser considerado um ser unicamente biológico a quem é suficiente a satisfação de suas necessidades vitais, pois "[...] muito rapidamente os reflexos incondicionados cedem lugar aos reflexos condicionados e esses, às aprendizagens sociais" (idem, p. 101).

No alicerce do curso de evolução da linguagem está o reflexo incondicionado das reações vocais, que apontam a pré-história da linguagem oral. Segundo Vygotski (2000), a primeira função da reação vocal é emocional. A segunda, por sua vez, revela-se quando a reação vocal se transforma em reflexo condicionado, exercendo a função de contato social, deixando de ter existência meramente biológica e ganhando existência social.

Lísina (1987), ao analisar a gênese das formas de comunicação na criança, afirma que há, de um lado, a total dependência do bebê, que produz reações 
primitivas de acordo com seus estados emocionais e necessidades básicas. De outro, existe o adulto, que identifica e atende a essas reações do recém-nascido. Trata-se, conforme a autora, da "iniciativa antecipadora do adulto" (idem, p. 282), que convida o bebê à atividade de comunicação, gerando nele a necessidade de se comunicar, diferente de outras necessidades que existiam outrora.

Paulatinamente, a passividade do recém-nascido é substituída por um interesse receptivo. Como mostra Vygotski (1996), o bebê passa a responder à influência de estímulos sensoriais. Segundo Elkonin (1960), a criança reage quando aparece o adulto e ouve sua voz, fixa o olhar em seu rosto, sorri, faz movimentos rápidos e intensos, mexendo braços e pernas. Essas são as primeiras reações emocionais positivas do bebê, denominadas complexo de animação, uma atividade de comunicação peculiar que surge por volta do terceiro mês de vida (idem; 1987b) e objetiva comunicar-se com os adultos por meios especiais, posto que o bebê carece do instrumento principal de comunicação: a linguagem.

Durante o segundo semestre do primeiro ano, o bebê passa do interesse receptivo ao interesse ativo e emerge uma busca ativa de estímulos. Nesse momento, segundo Martins (2012), aparecem as primeiras formas imitativas de movimentos e sons, que são a base para as formas de comportamento mais complexos. Assim, o trabalho pedagógico deve "[...] explorar as múltiplas possibilidades imitativas fornecendo os modelos (gestuais e sonoros) característicos das ações que envolvem a criança” (idem, p. 102).

A ausência da linguagem, por parte do bebê, e sua dependência total dos adultos ou, como Vygotski (2006, p. 286) indica, a "máxima sociabilidade" do bebê, expressam a situação social de desenvolvimento desse período. A situação social exige uma comunicação com os adultos, entretanto, “[...] é uma comunicação sem palavras, muitas vezes, silenciosa, uma comunicação de gênero totalmente peculiar" (idem, p. 286). É uma comunicação direta e emocional, pois o bebê ainda não tem como mediação para se comunicar a linguagem e, portanto, faz uso de gritos, choramingo, gestos e movimentos.

De acordo com Petrovski (1985), existem três etapas fundamentais no desenvolvimento da linguagem: a etapa pré-linguistíca (aproximadamente de dois meses até os onze meses); o domínio primário do idioma (aproximadamente dos 
onze meses até um ano e sete meses); e o domínio da estrutura gramatical da linguagem (aproximadamente de um ano e sete meses até os três anos). Essa primeira etapa no desenvolvimento da linguagem, denominada pré-linguística, caracteriza o primeiro ano de vida e precede o domínio da linguagem em si. Nesse momento, a linguagem é pré-verbal e pré-intelectual, marcada, fundamentalmente, pela independência entre pensamento e linguagem.

Para Petrovski (1985), o desenvolvimento da etapa pré-linguística, inicia-se pelo período dos ruídos e balbucios, aproximadamente até cinco meses. No segundo semestre do primeiro ano, aparecem as "pseudopalavras" quando o fluxo da linguagem da criança se decompõe em pedaços, com algumas sílabas unificadas por acentos, entonação e uma única articulação. Aos seis meses, aproximadamente, começa a balbuciar de forma prolongada, pronunciando sílabas, imitando o adulto, aquilo que Petrovski (1985) aponta como "pseudopalavras".

Por meio do balbucio, o bebê revela seu desejo de se comunicar com o adulto e aprende novos sons, aperfeiçoa o movimento dos lábios, da língua e da respiração, o que por sua vez, é essencial para assimilar os sons da língua materna (MUKHINA, 1996). Segundo Rubinstein (1967, p. 468), “[...] o balbucio prepara a possibilidade de aprender a dominar, no curso posterior, as reservas fonéticas da linguagem usada pelos adultos ao seu redor”.

Como mostra Petrovski (1985), os sons adquirem uma caraterística relevante, pois a composição sonora da linguagem do bebê é comparável à da língua materna, assim o pequeno reproduz de modo bem parecido a estrutura sonora das palavras. Contudo, ainda não se trata de palavras propriamente ditas, posto que não exercem a função de signos. Martins (2012) afirma que todo o período pré-linguístico é fundamental ao desenvolvimento da linguagem, mas destaca que as pseudopalavras, pela proximidade com as palavras da língua materna “[...] representam seus mais efetivos pré-requisitos" (idem, p. 106). A relevância das pseudopalavras consiste em que, com base nelas, "[...] ocorre a modelagem social requerida ao estabelecimento de relações entre objetos e fenômenos, sons e significados" (MARTINS, 2012, p. 106).

É no interior da comunicação emocional direta que se formam as bases para a formação de ações sensório-motoras de manipulação, ou seja, aparecem as 
premissas da atividade objetal manipulatória (ELKONIN, 1987b) ainda como linha acessória do desenvolvimento. Os bebês realizam com os objetos "[...] ações reiterativas e concatenadas que incluem o exame ativo do objeto ou qualquer outra atividade sensorial" (idem, 2009, p. 213).

Segundo Elkonin (1960), para que o bebê comece a entender o idioma, é importante a orientação visual no ambiente ao seu entorno. A compreensão inicial das palavras que os objetos denominam se expressa no bebê que gira sua cabeça, procura e estende as mãos na direção da coisa chamada pelo adulto que questiona: "Cadê o cachorro?". Esse tipo de pergunta provoca na criança reações de orientação e, quando o objeto é nomeado à criança, ao mesmo tempo em que o observa e atua com ele, "[...] após várias repetições, a criança estabelece a relação entre a palavra dita e o objeto definido por essa palavra" (idem, ibidem). O tom da pergunta, conforme Mukhina (1996) determina a compreensão que a criança tem da linguagem, sendo que a criança não procura o objeto apenas para ter contato com ele, mas para continuar em relação com o adulto.

É nesse sentido que Martins (2012, p. 105) evidencia como elemento importante das ações educativas "[...] a repetição como treino de memória". Mas esclarece que ensinar o bebê a falar não se reduz à repetição de palavras, mas exige a exposição a diferentes estimulações que ampliem as relações entre objetos, sons e significados. Pasqualini (2016) também afirma que é importante repetir os sons emitidos pelo bebê para que ele se mantenha interessado no desafio de emissão de sons à medida que os percebe como meio de relação emocional com o adulto.

No processo de ação conjunta com os adultos "[...] aparecem na criança a compreensão primária da linguagem humana, a necessidade da comunicação verbal e a pronúncia das primeiras palavras" (ELKONIN, 1960, p. 507). A imagem subjetiva da realidade está sendo construída e com ela o pareamento com o som. Como explica Vygotski (2001, p. 181), a princípio "[...] a criança assimila a conexão externa entre a palavra e o objeto e não a relação interna entre o signo e o significado”. Assim, a palavra (pseudopalavra) que designa o objeto, revela-se como mais uma de suas propriedades, uma mera extensão ou propriedade dele. Ao mesmo tempo que é uma palavra, ainda não é, mas sim uma expressão sonora que a ela corresponde e, portanto, nesse momento do desenvolvimento da fala, há 
ainda uma prevalência da face fonética sobre a semântica (MARTINS, 2016). Nessa direção, as pseudopalavras são o que Vigotski chama de seu equivalente funcional (MARTINS, 2013a) e abarcam não apenas o início do desenvolvimento da fala, pois correspondem às "palavras" que ainda não são conceitos.

Destarte, o desafio que se coloca ao trabalho pedagógico é que a palavra deixe gradativamente de "[...] ser mera extensão ou propriedade do objeto e, ultrapassando a conexão direta objeto-designação, promova a conversão da imagem do objeto em signo" (idem, p. 44), de modo que a criança entenda que a linguagem trata de categorias e não objetos particulares e principie processos de generalização. Para que isso aconteça, faz-se necessário que a criança "[...] abarque em uma mesma imagem cognitiva vários elementos que com ela se relacionam, o que corresponde à formação embrionária dos equivalentes funcionais dos conceitos" (MARTINS, 2013a, p. 171).

Antes de adentrarmos no próximo período, no qual acontece o domínio primário do idioma e da estrutura gramatical da linguagem, é preciso abordar o tipo específico de linguagem que aparece na passagem da atividade de comunicação emocional direta à atividade objetal manipulatória: a linguagem autônoma infantil.

\subsection{Da comunicação emocional direta à atividade objetal manipulatória: linguagem autônoma}

Para Vygotski (2006), a linguagem autônoma é uma lei que se observa no desenvolvimento verbal de todas as crianças, sendo um momento necessário ao desenvolvimento da linguagem autêntica. Trata-se de um período de transição, sendo uma "ponte de passagem" (idem, p. 339) entre o período pré-linguístico e o período verbal. Desse modo, a criança não tem ainda linguagem propriamente dita, ao mesmo tempo, não se encontra mais no período não-verbal à medida que começa a falar e se comunicar com os adultos com quem convive.

Conforme explica Vygotski (2006), o termo “autônomo” é utilizado em razão de algumas peculiaridades. Uma delas refere-se ao aspecto articulatório e fonético. Na forma exterior, as palavras da criança não coincidem, efetivamente, com as palavras da língua materna, podendo parecer ou não com elas, sendo mesmo palavras deformadas ou fragmentos delas. Além disso, as palavras 
autônomas não correspondem aos significados das palavras da língua materna. A criança fala, mas se utiliza de uma linguagem própria que não corresponde à linguagem autêntica tanto em seu aspecto fônico quanto semântico. Assim, a criança aplica uma única palavra e um significado que abarca todo um conjunto de coisas.

Há, pois, uma comunicação peculiar à medida que apenas se efetiva entre a criança e as pessoas próximas que compreendem o significado de suas palavras. Contudo, mesmo entendendo tais significados, as palavras apenas são compreensíveis pelos adultos na situação concreta, isto é, quando o objeto está no campo visual imediato, sendo impossível lidar com os objetos enquanto ausentes.

Com efeito, Vygotski considera que a diferença essencial entre a linguagem e a linguagem autônoma, para além das palavras soarem de formas diferentes, reside na estrutura, visto que as palavras autônomas carecem de significados permanentes. Portanto, não existe ainda simbolização, uma vez que o vocábulo, conforme Vygotski (idem, p. 337), “[...] significa tudo e, portanto, nada”.

Nesse sentido, a linguagem autônoma, além de ser uma etapa peculiar no desenvolvimento da linguagem, também o é no desenvolvimento do pensamento. Vygotski afirma que não há possibilidade de pensamento verbal à medida que a linguagem depende ainda da situação visual-direta, ou seja: quando a palavra não está inserida na situação, perde seu significado. Desse modo, a criança não pensa fora da situação visual-concreta e as palavras se unem apenas da maneira como os objetos estão unidos no campo sensório-perceptual. Portanto, o pensamento é dependente da percepção, daquilo que é percebido no entorno.

A relação possível entre as palavras isoladas também tem caráter peculiar, pois é uma linguagem desprovida de gramática, sem o procedimento de unir palavras e significados isolados em uma linguagem coerente e, desse modo, possui leis de coesão e união de palavras diferentes da nossa linguagem.

Conforme Luria (2001), as primeiras palavras da criança possuem estruturas amorfas e significados difusos, pois possuem caráter simpráxico, isto é, vinculam-se ao contexto imediato e são dependentes da situação, dos gestos ou mesmo da entonação. A palavra emancipa-se progressivamente desse contexto simpráxico, mas conserva durante bastante tempo laços com a situação prática e designa não o objeto, mas traços dele. O significado, pois, é amorfo à medida que 
não possui referência objetal e é difuso, pois ainda conserva estreita relação com a situação prática e mesmo designando um traço específico, faz referência a diferentes objetos que apresentam esse traço comum e se inserem em situação semelhante.

A primeira metade do segundo ano é o período de orações de uma só palavra. As palavras isoladas não denominam apenas um objeto, mas uma oração completa. Essa ideia se relaciona à ideia de Vigotski (2009) sobre o aspecto semântico e sonoro da linguagem que seguem diferentes leis de desenvolvimento, apresentando sentidos opostos. No aspecto fásico da linguagem, a criança caminha das partes para o todo. No aspecto semântico, por sua vez, caminha do todo para as partes. Nesse sentido, no aspecto fásico, a criança inicia com uma palavra que sintetiza duas ou três palavras, depois uma frase e dela para orações completas e, assim sendo, caminha da palavra para a oração. Entretanto, no aspecto semântico, essa palavra significa uma oração e, portanto, caminha da oração para a palavra.

$\mathrm{Na}$ segunda metade ou final do segundo ano de vida, a criança começa a desenvolver a morfologia a elementar da palavra, que ganha independência do contexto simpráxico, adquirindo referência objetal. Nesse momento em que a criança adquire formas morfológicas diferenciais, acontece um abrupto salto no vocabulário, pois se antes palavras eram amorfas e difusas, uma vez que podiam designar qualquer coisa, agora o significado se reduz e, diante disso, o vocabulário se amplia, uma vez que a criança necessita aprender novas palavras para designar corretamente os objetos, qualidades, ações e relações.

Segundo Luria (2001), a referência objetal se desenvolve no curso dos dois primeiros anos de vida e quando a palavra adquire referência objetal estável não significa que o desenvolvimento do significado da palavra terminou, mas como afirma Vigotski (2009), está apenas começando. Pela qualidade das mediações disponibilizadas, a criança supera a linguagem autônoma e avança para a linguagem autêntica. 


\subsection{Primeira Infância: atividade objetal e o entrecruzamento entre linguagem e pensamento}

Segundo Vygotski (2006), quando a linguagem autônoma desaparece, surge a linguagem autêntica. Conforme Martins (2012), o salto qualitativo mais decisivo desse período é que, além da função comunicativa, as palavras adquirem o status de signo, possibilitando a representação da imagem sob a forma de palavras. A criança amplia seu campo de atuação e a relação com o adulto deixa de ocupar a centralidade de suas percepções, emergindo como central a relação com os objetos, que supera a exploração meramente de suas propriedades sensoriais e passa a ter como objetivo a descoberta de suas funções sociais.

A situação social de desenvolvimento nessa idade, de acordo com Vygotski (2006), caracteriza-se pela dependência da situação concreto-visual. O autor explica que a percepção é a função predominante deste período e encontra-se em condições favoráveis de desenvolvimento. Ao lado da percepção, Vygostki destaca a linguagem como nova formação central, o que nos revela que o trabalho pedagógico com a linguagem é central nesse período. Ademais, de acordo com Mukhina (1996), de um a três anos é o período sensível para ensinar a criança a falar. Caso a criança, por qualquer razão, não comece a falar nesse período, assimilará a linguagem com maiores dificuldades no futuro.

O intenso desenvolvimento da linguagem transforma todos os processos psíquicos. (ELKONIN, 1960; MUKHINA, 1996). Vygotski (2006) mostra que as transformações na percepção estão ligadas ao desenvolvimento da linguagem e dos significados das palavras, uma vez que a aquisição da linguagem promove uma reorganização na percepção e em sua estrutura graças à generalização, analisando o percebido e categorizando-o. A percepção sem palavras é substituída paulatinamente pela verbal, isto é, pela percepção semântica.

A generalização se transforma no curso do desenvolvimento e, nesse sentido, a generalização de uma criança e a de um adulto são diferentes. Conforme Vygotski (idem), embora a criança designe objetos com as mesmas palavras que os adultos e suas palavras tenham significado, essa semelhança apenas acontece na aparência, pois na essência as estruturas de generalização são distintas, o que impulsiona a criança a novas vias de generalização e domínio da linguagem. 
Sabemos que cada palavra não se refere apenas a um objeto específico, mas a diversos objetos, que podem não ser parecidos. Conforme Elkonin (1960, p. 510), "[...] a compreensão de palavras que denominam objetos exteriormente diferentes conduz a criança à generalização". Aqui reside uma ideia fundamental ao trabalho pedagógico: "[...] a natureza das generalizações e os meios pelos quais são formadas dependem inteiramente de quais são as palavras que a criança aprende e a diversidade dos objetos denominados por elas" (idem, ibidem).

Conforme Mukhina (1996, p.138), “[...] a generalização dos objetos segundo sua função surge primeiro na ação, para depois fixar-se na palavra" e os primeiros portadores de generalização são os objetos. As palavras das crianças menores de três anos referem-se a objetos e ações. Nesse sentido, "[...] a palavra, o nome do objeto, expressa antes de mais nada, sua função, que perdura mesmo quando as propriedades externas mudam" (MUKHINA, 1996, p. 134). Por isso é mais complexo a aprendizagem de palavras que definem propriedades do objeto, posto que "[...] a criança deve abstrair o objeto e agrupar objetos muito distintos de acordo com traços que na maioria dos casos não importam para sua utilização" (idem, ibidem).

Nesse período é central o domínio dos procedimentos socialmente elaborados de ações com os objetos (ELKONIN, 1987b). Embora seja nuclear a relação da criança com os objetos, Elkonin pontua que os domínios dessas ações não se efetivam sem a participação dos adultos, isto é, sem um processo educativo. Não basta, pois, guiar os movimentos por meio de gestos, mas também por meio da linguagem. Conforme Mukhina (1996, p.124), “[...] o crescente interesse da criança pelos objetos leva-a a procurar a ajuda do adulto. É esse o principal estímulo que anima a criança a aprender a linguagem”.

O desenvolvimento da linguagem depende da qualidade da relação adultocriança, pois quando o adulto satisfaz os desejos da criança atendendo a seus gestos, não há a necessidade de falar. Nesse sentido, é preciso que o adulto provoque a fala da criança de modo que ela formule seus pedidos (MUKHINA, 1996). Assim, segundo Elkonin (1987b), a criança se transforma em ser falante, que faz uso de um léxico e formas gramaticais relativamente ricos. O autor afirma que a linguagem é utilizada pela criança para organizar a colaboração dos 
adultos na relação com os objetos na atividade conjunta. As ações com os objetos são, para a criança, o meio para organização da comunicação com os adultos.

É importante ter clareza que o intenso desenvolvimento da linguagem se dá pela atividade conjunta. A função social dos objetos e seus significados não estão dados de imediato pela manipulação. Portanto, a criança não os assimila sem a mediação dos significados atribuídos pelo adulto, que é o modelo e revela a função social do objeto. Contudo, é comum observarmos práticas pedagógicas que valorizam a manipulação sensorial de objetos, que, se por um lado é de extrema importância ao desenvolvimento, por outro, não raras vezes, coloca em segundo plano o papel do professor como aquele que nomeia e atribui significados àquilo que a criança manipula. Assim, a manipulação de objetos que defendemos como promotora de desenvolvimento não se limita à distribuição de objetos para manipulação espontânea e sensorial. (MARSIGLIA \& SACCOMANI, 2016).

Neste período, no tocante especificamente ao desenvolvimento da linguagem, são consideradas duas etapas. Na primeira, que abrange a primeira metade do segundo ano, desenvolve-se principalmente a compreensão da linguagem dos adultos voltada para a criança. $\mathrm{Na}$ segunda, que abrange a segunda metade do segundo ano e todo o terceiro ano, junto à compreensão, desenvolve-se com intensidade a linguagem ativa da criança. (ELKONIN, 1960).

Primeiramente, as crianças aprendem o nome das coisas e das pessoas que as rodeiam, depois aprendem as denominações das ações. Ao final do segundo ano compreendem quase tudo o que os adultos falam sobre o que as rodeiam no imediato ou suas próprias ações (ELKONIN, 1960). Nesse momento, a criança enriquece seu vocabulário, desenvolve a pronúncia das palavras e assimila o sistema gramatical da língua materna (MUKHINA, 1996). Petrovski (1985) afirma que de um ano e sete meses (quando finaliza a etapa do domínio primário do idioma) até os três anos, é o período do domínio da estrutura gramatical da linguagem. Elkonin (1960) sintetiza que na segunda metade do segundo ano, acompanhando um aumento de palavras, aparecem as primeiras orações de duas ou três palavras, as quais apenas são compreendidas pelos adultos que convivem com a criança. O final do segundo ano aponta o começo de uma nova etapa: a criança aprende a estrutura gramatical da oração; mesmo que as orações sejam curtas, as palavras se coordenam segundo regras gramaticais. 
Diante disso, Martins (2012) enfatiza que o trabalho pedagógico deve ter como objetivo favorecer a compreensão e uso da linguagem em seus aspectos fonéticos, léxicos e gramaticais, tendo em vista a correta articulação dos sons constitutivos das palavras, a ampliação do vocabulário, a ordenação e articulação das palavras nas orações. Essas aquisições, segundo a autora, são importantes ao desenvolvimento da leitura e escrita.

Segundo Elkonin (1960), ao final do terceiro ano, as palavras podem chegar de 800 a 1000. No conteúdo do vocabulário se encontram quase todas as partes da oração e, entre elas, seus tipos fundamentais, inclusive as compostas por conjunção. Mukhina (1996) também afirma que, por volta de três anos, a criança "[...] conhece mais de mil palavras, pronuncia frases coerentes, faz infinitas perguntas como prova do vivo interesse pelo que a cerca”. Conforme Elkonin (1960), no final desse período, a linguagem alcança um nível tão elevado que permite regular a conduta da criança e ensinar a utilizar objetos, não mais apenas mostrando diretamente o que fazer, mas por meio de indicações verbais.

Segundo Elkonin (1960), além de compreender a linguagem dos adultos que organizam as atividades práticas, a criança compreende narrações que descrevem acontecimentos e ações conhecidas. Compreender aquilo que os adultos falam sobre o que não é percebido imediatamente é uma conquista importante e cria a possibilidade de utilizar a linguagem como instrumento de transmissão de conhecimentos, o que é uma das principais funções da linguagem para o gênero humano.

No fim da primeira infância, o círculo de relações e a atividade verbal se ampliam, de modo que as crianças falam não apenas com as pessoas próximas, mas também com outras crianças e adultos. As crianças conquistam a capacidade de memorizar pequenos versos e contos, reproduzindo-os com precisão. Como o autor indica, essa capacidade é fundamental para enriquecer a linguagem e, portanto, destacamos que esse é um dos focos do trabalho pedagógico.

À medida que a criança aprende a operar com os objetos, adquire cada vez mais autonomia em suas ações e, segundo Elkonin (1960), começa a interessar-se por reproduzir as ações dos adultos, querendo atuar com os mesmos objetos que os adultos atuam. Assim, as premissas para a brincadeira de papéis são formadas e a ação lúdica se revela quando a criança, paulatinamente, liberta-se das 
condições específicas de uso do objeto na direção de um uso livre, até que emerge a substituição de um objeto por outro.

Nesse sentido, segundo Varotto (2013), é importante nesse momento o trabalho com a literatura de modo que a criança possa interagir com a história, por meio da utilização de fantoches, materiais e objetos que representem os personagens sem que necessariamente se pareçam com eles. Além disso, é importante promover ações em que as próprias crianças sejam capazes de recontar as histórias com tais objetos. O fato de os objetos não se parecerem com os personagens e, portanto, representá-los, explora a linha acessória do desenvolvimento, impulsionando a criança para atividade seguinte.

\subsection{Idade pré-escolar: brincadeira de papéis e a internalização da linguagem}

Na brincadeira de papéis, a atividade da criança se complexifica e já não basta aprender o uso e funções dos objetos, ganhando destaque as relações sociais nas quais os objetos estão presentes e a criança é impedida de atuar de forma mais efetiva. Leontiev (2012b) define a brincadeira como uma atividade cujo motivo está no próprio processo e, portanto, não pode ser avaliada pelo seu produto, mas pelo seu conteúdo. É por essa característica não produtiva da brincadeira de papéis que as operações exigidas pela atividade e os objetos podem ser substituídos sem prejuízo ao conteúdo da ação.

A ação da criança na brincadeira corresponde à ação realizada pelos adultos, ao mesmo tempo, as operações correspondem às características concretas do objeto que está empregando para brincar. Pela necessidade de agir como os adultos, há um tipo de substituição, uma vez que um objeto pertencente ao mundo dos objetos diretamente acessíveis a ela substitui, de modo imaginário, o objeto com o qual ela não pode operar. (LEONTIEV, 2012b)

A complexificação da brincadeira depende da maneira como a criança se apropria da atividade social dos adultos. Num primeiro momento o conteúdo da brincadeira de papéis é a ação real dos adultos com os objetos. Em seguida, os objetos passam a ocupar segundo plano, emergindo como essencial a relação entre as pessoas. Por fim, o nuclear é o respeito às regras derivado do papel assumido (MUKHINA, 1996). 
O importante na realização da brincadeira de papéis não é o prazer, como querem algumas interpretações que romantizam, naturalizam e idealizam a infância, mas a capacidade de assumir adequadamente o papel. Segundo Vigotski (2008), a brincadeira exige que a criança aja contra seu impulso imediato e organize sua conduta de acordo com as regras. Segundo Elkonin (1987a, p. 98), a brincadeira de papéis é "[...] uma escola peculiar de limitação dos impulsos imediatos". É nesse sentido que a autorregulação da conduta se destaca como umas das principais conquistas que principiam nesse período, o que se constitui como premissa para a atividade de estudo na idade escolar.

Segundo Mukhina (1996), a criança precisa se comunicar e prever as ações dos companheiros, atuando a depender delas. Como explica Elkonin (1960), a criança se submete às regras de relações mútuas existentes na brincadeira. É nesse sentido que Mukhina (1996) afirma que há a necessidade de comunicar-se com os demais participantes e, desse modo, desenvolve a linguagem coerente, uma vez que precisa expressar seus desejos e compreender as instruções verbais recebidas.

Com efeito, o professor deve observar do que e como as crianças brincam, não no sentido de evitar interferência, pelo contrário: é preciso observar e avaliar para intervir. Conforme Marcolino (2013), o professor pode participar da brincadeira, propor novos temas e atuar também como personagem, servindo de modelo e, aqui, acrescentamos, modelo também no que se refere à linguagem. É preciso, pois, enriquecer a realidade das crianças para complexificar a brincadeira.

Dentro desse período, destacam-se como linhas acessórias as atividades produtivas (desenho, construção, modelagem, recorte, trabalhos manuais etc.). Diferente da brincadeira de papéis, em que o motivo está no próprio processo, o propósito das atividades produtivas, como o próprio nome indica, é ter um produto. Portanto, o trabalho pedagógico deve propor atividades que demandem planejamento e que seus resultados estejam cada vez mais próximos de seus projetos (ELKONIN, 1960).

Com efeito, na idade pré-escolar, a criança se torna mais independente, sua atividade se complexifica, o que exige dela uma linguagem mais complexa e maior domínio para se comunicar, bem como o enriquecimento de seu vocabulário. Vale 
ressaltar, conforme Elkonin (1974, p. 130), que o “[...] crescimento de vocabulário, bem como o domínio da estrutura gramatical, dependem diretamente das condições de vida e educação". Ademais, o autor ressalta que o domínio sobre a composição verbal da língua materna não se limita pelo aspecto quantitativo, mas também pelo desenvolvimento dos significados. O vocabulário representa a matéria prima pela qual a combinação de palavras, seguindo as regras gramaticais, pode servir ao objetivo de interação social.

Segundo Mukhina (1996), ao final da idade pré-escolar, a criança começa a assimilar a estrutura da linguagem, que será essencial ao desenvolvimento da fala e da escrita. Assim, o vocabulário se enriquece não apenas em relação aos substantivos, mas também verbos, adjetivos, pronomes, numerais e conjunções subordinativas. Esse enriquecimento do vocabulário é acompanhado de maior capacidade para construir frases seguindo as regras gramaticais da língua, chegando a dominar regras sintáticas e morfológicas. Segundo Elkonin (1960b), a criança aprende a usar todos os tipos de orações, tanto as simples como as compostas por conjunções, assimila o sistema morfológico do idioma, declinações e conjugações, compreendendo o significado das diferentes formas gramaticais.

As crianças, segundo o autor, começam a entender as regras da prosódia, o que possibilita um ensino dedicado pronúncia. Pela observação da fonética, “[...] começam a distinguir e diferenciar sons isolados do idioma, o que é muito importante para o estudo posterior da leitura e da escrita, o que requer a decomposição da palavra em sons" (idem, 517), que se vincula ao desenvolvimento da consciência fonológica.

A criança, nesse período, é capaz de desenvolver a linguagem coordenada ou contextual (ELKONIN, 1960; ELKONIN, 1974; MUKHINA, 1996), pela qual expõe seus pensamentos de forma coerente, verbalizando descrições nas quais há orações articuladas, o que também contribuirá para a leitura e escrita. Em relação com essa ideia, Mukhina (1996) cita a superação da linguagem situacional em direção à linguagem contextual. A primeira é pouco organizada e a comunicação surge motivada por uma situação concreta; geralmente, é compreendida somente pelas pessoas envolvidas no diálogo e tem muitos advérbios e expressões estereotipadas, como a palavra "aí". A autora cita como exemplo o desprendimento do sujeito, que fica subentendido e, geralmente, é 
substituído por pronomes e apenas os sujeitos inseridos na situação sabem a quem se refere. Na relação com o interlocutor, que faz perguntas sobre o conteúdo do relato, a criança esforça-se para dar uma explicação melhor e tornar sua linguagem mais compreensível.

A depender da qualidade das mediações, a criança desenvolve a linguagem contextual, na qual descreve a situação com um número suficiente de detalhes que permitem ao interlocutor compreendê-la sem vivenciá-la. (MUKHINA, 1996). Isso não significa que a linguagem situacional deixa de existir. Ademais, não apenas as crianças continuam a fazer uso dela, como também adultos o fazem em situações cotidianas. O que é importante garantir é que o uso dessas modalidades de linguagem pela criança passe a ter um caráter mais voluntário e socialmente apropriado.

A linguagem contextual se desenvolve a partir de um ensino em que a criança sinta necessidade de novos meios linguísticos para se comunicar. Portanto, é preciso possibilitar situações em que a linguagem contextual se faça necessária, isto é, ações em que a criança sinta a necessidade de construir orações articuladas e coerentes com riqueza cada vez maior de detalhes, superando cada vez mais suas formas de comunicação em direção ao uso mais consciente e voluntário da linguagem. A linguagem coordenada, segundo Elkonin (1974), desenvolve o domínio da estrutura gramatical da língua materna. Assim sendo, "[...] de grande importância não é apenas ouvir gramaticalmente correta e foneticamente precisa a linguagem, mas também a prática independente da criança em utilizar todas as formas de linguagem coordenada."

Elkonin (idem) afirma que a criança é capaz de transmitir suas impressões ao adulto. O autor refere-se à "linguagem explicativa" (idem, p. 112), como um tipo de "monólogo-história" sobre aquilo que a criança vivenciou. Mukhina (1996) cita também a linguagem explicativa, que se desenvolve na idade pré-escolar, quando a criança precisar explicar as regras de um jogo, funcionamento de um brinquedo etc. Com efeito, o ensino deve ser organizado de forma que se faça necessária uma relação mais consciente da criança com sua própria expressão oral.

A linguagem, além de desenvolver-se enquanto meio de comunicação, desempenha outra função essencial: meio de planejamento e regulação da 
conduta (MUKHINA, 1996). Em seus estudos, Vigotski (2009) mostrou que em situações em que desafios se apresentavam, a linguagem egocêntrica aumentava em comparação a situações em que esses desafios estavam ausentes. Assim, a linguagem egocêntrica "[...] se torna pensamento na verdadeira acepção do termo, melhor dizendo, assume a função de operação de planejamento, de solução de tarefas que surgem no comportamento" (idem, p. 136).

Enquanto na atividade objetal a criança utilizava a linguagem para requerer a ajuda do adulto na manipulação de objetos, desde o fim da primeira infância, ao resolver problemas, a criança pronuncia palavras, sem se dirigir a alguém, mas dirigindo-se a si própria (MUKHINA, 1996). Tratam-se de “[...] exclamações que expressam a atitude da criança diante do que ocorre, ou então palavras com que ela explica a operação e seus resultados" (idem, p. 242). De acordo com Mukhina (idem), na idade pré-escolar, além dessa linguagem acompanhar as ações da criança, também precede a ação e a orienta. Aos poucos, essa linguagem se reduz, porém isso não significa que as ideias deixam de ter forma linguística, mas sim que essa linguagem se internaliza e permanece com a função de planejamento. Segundo Vigotski (2009), a linguagem egocêntrica não meramente desaparece, mas é interiorizada, transforma-se em linguagem interior.

Deveras, a educação pré-escolar tem o papel de contribuir para que a criança supere gradativamente a relação espontânea com a linguagem e caminhe para uma relação mais consciente e intencional, que pressupõe autodomínio da conduta, aspecto fundamental na transição à idade escolar.

\section{Considerações finais}

Sem a pretensão de esgotar a compreensão do desenvolvimento da linguagem na infância e o papel da educação nesse processo em toda sua abrangência, buscamos oferecer um panorama das características da linguagem e suas possibilidades em cada atividade-guia que medeia a vida da criança na educação infantil.

$\mathrm{Na}$ comunicação emocional direta há, de um lado, uma comunicação privada de linguagem, se considerado o ponto de vista do bebê, mas de outro, existe o adulto, que lhe dirige a palavra. Ainda que o bebê não faça uso da 
linguagem, a linguagem do adulto move o desenvolvimento na direção da apropriação da linguagem. Nesse período, destaca-se a importância da orientação visual no ambiente, a repetição dos sons emitidos pelo bebê, cantar, conversar e direcionar a observação e exploração de diferentes objetos, descrever aquilo que se faz, nomear partes do corpo e objetos durante o diálogo com os pequenos.

$\mathrm{Na}$ atividade objetal, dadas as condições de vida e educação, acontece a superação da conexão direta objeto-designação, promovendo a conversão da imagem do objeto em signo, entendendo que a linguagem trata de categorias e não objetos particulares. À medida que a linguagem é utilizada pela criança para organizar a colaboração dos adultos na relação com os objetos, deve-se organizar ações em que a criança explore objetos, seja incentivada a falar e se expressar, amplie o vocabulário, desenvolva a pronúncia e articulação das palavras, enriqueça o domínio da estrutura gramatical da linguagem, memorize pequenos versos, parlendas e cantigas, bem como se expresse por meio da linguagem oral.

$\mathrm{Na}$ idade pré-escolar, espera-se que a criança conquiste a linguagem contextual e, para tanto, é preciso propor ações pedagógicas em que a criança amplie o vocabulário em diferentes contextos, exponha ideias, construa textos oralmente, narre histórias e fatos, reconte histórias, argumente, explique regras de um jogo ou brincadeira, realize entrevistas, retome tarefas já elaboradas e explique suas produções, enfim, construa orações articuladas e coerentes com riqueza crescente de detalhes e conquiste maior domínio da estrutura gramatical da linguagem.

Objetiva-se, pois, que a criança construa uma relação menos espontânea com a linguagem, caminhando em direção a uma relação cada vez mais voluntária com a linguagem oral. Para tal avanço, também é essencial a complexificação da brincadeira de papéis, que desenvolve a linguagem coerente e o audomínio da conduta.

O professor precisa ter uma visão geral sobre o desenvolvimento, levando em consideração o movimento de um período em direção aos períodos seguintes e o papel da educação escolar na promoção do desenvolvimento. Cabe, portanto, à educação infantil, organizar a atividade da criança de modo a promover a apropriação e domínio voluntário do idioma falado, requalificando a relação da 
criança com a linguagem oral, tendo em vista as máximas possibilidades de desenvolvimento de acordo com as especificidades da faixa etária.

\section{Referências}

ELKONIN, D.B. Desarrollo psíquico del niño desde el nacimiento hasta el ingresso en la escuela. In: MIRNOV, A.A. e cols. (orgs). Psicología. México: Grijalbo, 1960, p.504-522.

Development of speech. In: Zaporozhets, A. V., Elkonin, D. B. (Eds.), The psychology of preschool children. Cambridge, MA: The MIT Press. 1974. p. 111185.

LEONTIEV, A. Uma contribuição à teoria do desenvolvimento da psique infantil. In: VIGOTSKII, L.S.; LURIA, A. \& LEONTIEV, A. Linguagem, desenvolvimento e aprendizagem. 12.ed. São Paulo: Ícone, p.59-83, 2012a.

- Os princípios psicológicos da brincadeira pré-escolar. In: VIGOTSKII, L.S.; LURIA, A. \& LEONTIEV, A. Linguagem, desenvolvimento e aprendizagem. 12.ed. São Paulo: Ícone, p.119-142, 2012 b.

LURIA, A. R. Pensamento e linguagem: as últimas conferências de Luria. Porto Alegre: ARTMED, 2001.

LÍSINA, M. La génesis de las formas de comunicación en los niños. In: DAVÍDOV, V.; SHUARE, M. (Org.) La psicologia evolutiva e pedagógica en la URSS: Antología. Moscú, URSS: Editorial Progreso, 1987. p. 274-298.

MARCOLINO, S. A mediação pedagógica na educação infantil para o desenvolvimento da brincadeira de papéis sociais. Tese de Doutorado, Programa de Pós-Graduação em Educação, Universidade do Estado de São Paulo, Marília, 2013.

MARSIGLIA, A. C. G., SACCOMANI, M. C. Contribuições da periodização históricocultural do desenvolvimento para o trabalho pedagógico histórico-crítico. In: MARTINS, L. M., ABRANTES, A. A., FACCI, M. G. D. (Org.). Periodização histórico-cultural do desenvolvimento psíquico: do nascimento à velhice. Campinas: Autores Associados, 2016, p. 343-368.

MARSIGLIA, A. C. G.; SAVIANI, D. Prática pedagógica alfabetizadora à luz da psicologia histórico-cultural e da pedagogia histórico-crítica. In: Psicologia em Estudo, Maringá, v. 22, n. 1, jan./mar. 2017. p. 3-13.

MARTINS, L. M. Psicologia histórico-cultural, pedagogia histórico-crítica e desenvolvimento humano. In: MARTINS, L. M., ABRANTES, A. A., FACCI, M. G. D. (Org.). Periodização histórico-cultural do desenvolvimento psíquico: do nascimento à velhice. Campinas: Autores Associados, 2016a, p. 13-34. 
O desenvolvimento do psiquismo e a educação escolar: contribuições à luz da psicologia histórico cultural e da pedagogia histórico-crítica. Campinas: Autores Associados, 2013a.

Os fundamentos psicológicos da pedagogia histórico-crítica e os fundamentos pedagógicos da psicologia histórico-cultural. Germinal: Marxismo e Educação em Debate, Salvador, v. 5, n. 2, p. 130-143, dez. 2013 b.

O ensino e o desenvolvimento da criança de zero a três anos. In: ARCE, A.; MARTINS, L. M. (Orgs.). Ensinando aos pequenos de zero a três anos. Campinas - SP: Alínea, 2012, p. 93-121.

MUKHINA, V. Psicologia da idade pré-escolar: um manual completo para compreender e ensinar desde o nascimento até os sete anos. São Paulo: Martins Fontes, 1996.

PASQUALINI, J. C. O desenvolvimento do psiquismo e o ensino escolar. In: PASQUALINI, J.C.; TSUHAKO, Y. N. (Org.). Proposta pedagógica da Educação Infantil do Sistema Municipal de Ensino de Bauru/SP.1ed. Bauru: Secretaria Municipal de Educação-Bauru, v. 1, 2016, p.69-100.

PASQUALINI, J. C.; ABRANTES, A. A. Forma e conteúdo do ensino na educação infantil: o papel do jogo protagonizado e as contribuições da literatura infantil. Germinal: Marxismo e Educação em Debate, Salvador, v.5, n.2, p.13-24, dez. 2013.

RUBINSTEIN, S. L. Princípios de psicologia general. México: Grijalbo, 1967.

SACCOMANI, M. C. S. A importância da educação pré-escolar para o desenvolvimento da linguagem oral e escrita: contribuições à luz da pedagogia histórico-crítica e da psicologia histórico-cultural. Tese de doutorado apresentada ao Programa de Pós-Graduação em Educação Escolar. Faculdade de Filosofia e Letras. UNESP campus de Araraquara, 2018.

VIGOTSKI, L.S. A construção do pensamento e da linguagem. São Paulo: Martins Fontes, 2009.

VYGOTSKI, L.S. Obras escogidas. Tomo II. Madrid: Visor, 2001.

Obras escogidas. Tomo III. Madrid: Visor, 2000.

Obras escogidas. Tomo IV. Madrid: Visor, 2006. 